Bot. 56: 375-382, 2005

Pogoryelov, D., Yildiz, O., Faraldo-Gomez, J.D. et al.: Highresolution structure of the rotor ring of a proton-dependent ATP synthase. - Nat. Struct. Mol. Biol. 16: 1068-1073, 2009.

Porra, R.J., Thompson, W.A., Kriedemann, P.E.: Determination of accurate extinction coefficients and simultaneous equations for assaying chlorophylls $a$ and $b$ extracted with four different solvents: verification of the concentration of chlorophyll standards by atomic absorption spectrometry. - BBABioenergetics 975: 384-394, 1989.

Roach, T., Krieger-Liszkay A.: The role of the PsbS protein in the protection of photosystems I and II against high light in Arabidopsis thaliana. - BBA-Bioenergetics 1817: 2158-2165, 2012.

Ruban, A.V., Pesaresi, P., Wacker, U. et al.: The relationship between the binding of dicyclohexylcarbodiimide and quenching of chlorophyll fluorescence in the light-harvesting proteins of photosystem II. - Biochemistry 37: 11586-11591, 1998.

Singh-Rawal, P., Jajoo, A., Mathur, S. et al.: Evidence that pH can drive state transitions in isolated thylakoid membranes from spinach. - Photoch. Photobio. Sci. 9: 830-837, 2010.

Tikkanen, M., Gollan, P.J., Suorsa, M. et al.: STN7 operates in retrograde signaling through controlling redox balance in the electron transfer chain. - Front. Plant Sci. 3: 1-11, 2012.

Tokutsu, R., Minagawa, J.: Energy-dissipative supercomplex of photosystem II associated with LHCSR3 in Chlamydomonas reinhardtii. - P. Natl. Acad. Sci. USA 110: 10016-10021, 2013.

Waloszek, A., Wieckowski, S.: Effects of pH on the kinetics of light-dependent proton flux in thylakoids isolated from lettuce leaves. - Plant Sci. 166: 479-483, 2004.

Walters, R.G., Ruban, A.V., Horton, P.: Identification of proton active residues in a higher plant light-harvesting complex. P. Natl. Acad. Sci. USA 93: 14204-14209, 1996.

Wilk, L., Grunwald, M., Liao, P.N. et al.: Direct interaction of the major light-harvesting complex II and PsbS in nonphotochemical quenching. - P. Natl. Acad. Sci. USA 110: 54525456, 2013.

Wollman, F.A.: State transitions reveal the dynamics and flexibility of the photosynthetic apparatus. - EMBO J. 20: 3623-3630, 2001.

\title{
Erratum to: Accumulation of photosynthetic pigments in Larix decidua Mill. and Picea abies (L.) Karst. cotyledons treated with 5-aminolevulinic acid under different irradiation
}

\author{
N. MAXIMOVÁ ${ }^{*,+}$ and L. SLOVÁKOVÁ** \\ Institute of High Mountain Biology, University of Žilina, 05956 Tatranská Javorina 7, Slovak Republic* \\ Department of Plant Physiology, Faculty of Natural Sciences, Comenius University, Mlynská dolina, \\ 84215 Bratislava, Slovak Republic ${ }^{* *}$
}

\section{Erratum to: Photosynthetica DOI: $10.1007 / s 11099-014-0019-8$}

The acknowledgements were completed in the corrected version:

Acknowledgements: This work was supported by Structural Funds of EU Project of the Agency of the Ministry of Education, Science, Research and Sport of the Slovak Republic, Bratislava, ITMS No. 26110230078 and the Slovak Research and Development Agency (APPV-20-020805). We thank Y. Fujita, J.-D. Rochaix, and B. Grimm for providing the primary antibodies used in this work. We thank MSc Robin Rigg for English correction.

The publisher and authors apologize for these errors and for inconveniences they may have caused.

The online version of the original article can be found under doi: 10.1007/s11099-014-0019-8

${ }^{+}$Corresponding author; e-mail: maximova@uniza.sk 